\title{
“Que no es servicio del rey”. Milicias y trabajo en obras públicas. Buenos Aires, 1750-1800
}

Resumen: La historiografía colonial tendió a considerar las milicias americanas como simples unidades militares. No obstante, un atento análisis del funcionamiento cotidiano de las guarniciones de la frontera de Buenos Aires permite evidenciar el uso de estas milicias como mano de obra dedicada a la fortificación. El presente artículo indaga las relaciones sociolaborales emergidas en torno a las milicias de vecinos reconociendo una serie de prácticas sociales y costumbres que facilitaron su existencia, así como los momentos y modos en que los plebeyos locales resistieron estas mismas relaciones sociales.

Palabras clave: milicias, fuerza de trabajo, frontera, vicios, plebeyos.

\section{"Que no es servicio del rey". Militias and labour in public works. Buenos Aires, 1750-1800}

Abstract: Colonial historiography has considered American militias mostly as simple military units. Nevertheless, thoughtful analysis of the daily functioning of frontier garrisons in Buenos Aires shows the use of these militias as manpower dedicated to fortification works. The current article is an inquiry into the social and labour relations which emerged around the militias and acknowledges the social practices and customs that facilitated the existence of militias, as well as the moments and ways in which commoners resisted these social relations.

Keywords: militias, labour power, frontier, vices, plebeians.

\section{"Que no es servicio del rey". Milícias e trabalho em obras públicas. Buenos Aires, 1750-1800}

Resumo: A historiografia colonial tende a considerar as milícias americanas como meras unidades militares. No entanto, uma análise atenta do funcionamento diário das guarnições da fronteira de Buenos Aires permite demonstrar o uso dessas milícias como força de trabalho dedicada à fortificação. 0 presente artigo explora as relações sócio-trabalhistas surgidas em torno de milícias de bairro, reconhecendo uma série de práticas e costumes sociais que permitiram sua existência, bem como os momentos e formas pelas quais os plebeus locais resistiram a essas mesmas relações sociais. Palavras-chave: milícias, força de trabalho, fronteira, vícios, plebeus.

Cómo citar este artículo: Eduardo Iraola, "'Que no es servicio del rey’. Milicias y trabajo en obras públicas. Buenos Aires, 1750-1800”, Trashumante. Revista Americana de Historia Socia/14 [2019]: 54-75.

DOI: 10.17533/udea.trahs.n14a03

Fecha de recepción: 28 de agosto de 2018

Fecha de aprobación: 30 de enero de 2019

$\circledast A$

Eduardo Iraola: Doctor en Historia por la Universidad Nacional de Luján. Actualmente es docente e investigador de la Universidad Nacional de Luján y de la Universidad Nacional de la Patagonia Austral.

Correo electrónico: profeduardoiraola@gmail.com 


\title{
"Que no es servicio del rey". Milicias y trabajo en obras públicas. Buenos Aires, 1750-1800
}

\author{
Eduardo Iraola
}

\section{Introducción}

El Buenos Aires colonial suponía un número considerable de habitantes Evinculados a las labores castrenses. Más allá de la supuesta militarización iniciada por las invasiones inglesas, ${ }^{1}$ la reducida jurisdicción porteña implicó desde sus orígenes un cuantioso número de soldados regulares y milicianos de servicio en las guarniciones de la ciudad, así como recursos y el establecimiento de los más lejanos puestos de frontera que tendieron a incrementarse durante el siglo XVIII. ${ }^{2}$ En particular, las fuerzas del ejército regular se concentraban en la ciudad de Buenos Aires, mientras que los milicianos eran mayoría en la campaña y la frontera. ${ }^{3}$

Una de las formas más antiguas de servicio militar lo constituyeron las milicias, en particular, las provinciales hispánicas han sido periodizadas antes y después del siglo XVIII. Las distingue su carácter popular para la defensa local del territorio y la función supletoria de las fuerzas regulares basada en la noción de servicio al rey. ${ }^{4} \mathrm{La}$ Corona tenía el objetivo de lograr que sus posesiones coloniales pudieran sustentar su propia defensa y para ello impuso esta obligación a todo aquel que poseyera la condición de vecindad, aunque también existieron milicias de pardos, mulatos, etcétera.

Desde el siglo XVII las milicias de vecinos prestaban servicios que debían estar vinculados a la defensa o protección local, ${ }^{5}$ aunque se los utilizó en movilizaciones

1. Tulio Halperín Donghi, "Militarización revolucionaria en Buenos Aires, 1806-1815”, El ocaso del orden colonial en Hispanoamérica, comp. Tulio Halperín Donghi (Buenos Aires: Sudamericana, 1978) 125-127.

2. Eugenia Néspolo, Resistencia y complementariedad. Gobernar en Buenos Aires. Luján en el siglo XVIII: un espacio políticamente concertado (Buenos Aires: Escaramujo, 2012) 66-89.

3. Manuel Chust y Juan Marchena Fernández, eds., Las armas de la nación: independencia y ciudadanía en Hispanoamérica (1750-1850) (Madrid: Iberoamericana / Vervuert, 2007) 17.

4. José Contreras Gay, "Las milicias en el Antiguo Régimen. Modelos, características generales y significado histórico", Chronica Nova 20 (1992): 76-78.

5. Néspolo 551. 
armadas fuera de Buenos Aires, lo que ocasionó la protesta del cabildo. ${ }^{6}$ El manejo de las milicias de vecinos se modificó por la práctica cotidiana que continuó empleándolos y se consagró en norma dentro de las reformas borbónicas. ${ }^{7}$ Ahora bien, la práctica de servirse de los vecinos significó para las autoridades coloniales la obligación de sostener la manutención de estos (reconstitución de esa fuerza de trabajo).

En 1752 se instaló la Comandancia General de Fronteras de Luján para organizar y regir el conjunto de las guarniciones, institución que nos legó un cúmulo considerable de documentación oficial. Entre 1750 y 1800 se extendió y consolidó el uso de los vecinos en el servicio de milicias, proceso que sería trastocado con el inicio del siglo XIX y las consiguientes convulsiones internacionales. ${ }^{8}$ La frontera bonaerense implicó la construcción de estructuras militares de madera y ladrillos de adobe para contener las incursiones de las parcialidades indígenas que dispersas en la inmensa pampa igualmente entraban y salían con o sin permiso.

La superficie de ocupación efectiva se reducía a una franja de tierra aledaña al río Paraná y sus afluentes. En sentido paralelo y al sur de dicho río se encuentra el Salado, que representaba una auténtica barrera natural contra la circulación de las parcialidades indígenas. De este modo, quedaba un único corredor para ingresar a Buenos Aires: el espacio comprendido entre la naciente de dicho río y las costas del Paraná, que dejaba expuesta a los ataques a la población de esta zona.

A mediados del siglo XVIII hacer uso de las milicias de vecinos suponía una ración alimentaria de carne, bizcocho y "vicios". ${ }^{9}$ Estas eran las condiciones tanto para la movilización militar como para el sostenimiento cotidiano, ya que eran parte de la costumbre. ${ }^{10}$ Los intereses de los notables locales y de la élite porteña entraban en consonancia para servirse del miliciano en una serie de tareas cada vez más amplia. En particular, los emplearon tanto en labores de construcción pública (y defensiva) como en el saneamiento de ríos o la reparación de fortificaciones.

De este modo, emergieron prácticas sociales que expresaron las condiciones de las relaciones sociolaborales. El objetivo será revisar el uso y manutención de los milicianos en este tipo de tareas en la frontera bonaerense. La propuesta es que las élites locales y citadinas explotaron laboralmente a las milicias de vecinos sin

6. "Cabildo del 22 de septiembre de 1729", Acuerdos del Extinguido Cabildo de Buenos Aires, serie II, t.VI (Buenos Aires: Archivo General de la Nación, 1928) 93-96.

7. Allan J. Kuethe, "Las milicias disciplinadas en América", Soldados del Rey. El ejército borbónico en América colonial en vísperas de la Independencia, eds. Allan J. Kuethe y Juan Marchena Fernández (Castelló de la Plana: Universitat Jaume I, 2005) 101-126.

8. Néspolo 93-119.

9. En otros trabajos hemos podido definir los vicios como un conjunto de bienes constituidos socialmente entre los que se consideraban el aguardiente, el vino, la yerba mate, el tabaco y los naipes (juegos). Véase Eduardo Iraola, "Borrachera y violencia en las milicias de la frontera del Buenos Aires tardocolonial", Anuario del PROEHAA 1.1 (2015): 20-26.

10. Eduardo Iraola, "El precio de la fuerza de trabajo en la etapa tardo-colonial. Hegemonía, paternalismo y costumbres" (Ponencia, XII Congreso Nacional de Estudios del Trabajo, Asociación Argentina de Especialistas en Estudios del Trabajo / Universidad de Buenos Aires, 2015). 
distinción de castas y apenas abonando la reconstitución de su fuerza de trabajo, lo que convirtió el servicio defensivo en una forma de apropiación del excedente laboral y provocó que el vecino miliciano deviniese en un miliciano-trabajador. Los milicianos y los soldados regulares fueron usados como mano de obra, mientras que el proceso de trabajo tendió a homogeneizar las castas y generó un colectivo plebeyo por oposición a sus inmediatos dominadores.

El abordaje se presenta como una reconsideración del servicio miliciano a la luz de las relaciones laborales, debido a que se parte del supuesto de que las castas dominadas fueron utilizadas y tratadas por las élites y notables locales sin distinción. De este modo, los paisanos hispano-criollos, indígenas y afrodescendientes fueron reducidos por la práctica cotidiana a un colectivo plebeyo que era fruto más de la repulsión que de la identidad propia. Mientras que la historiografia tendió a reproducir la estructura jurídico-legal de la época colonial y redujo las relaciones laborales a los espacios productivos. ${ }^{11}$

La sociedad ofrece versiones objetivadas de la realidad que esconden el verdadero sustrato en el cual una parte de ella se beneficia del resto de la población. ${ }^{12}$ Por este motivo, no podemos adentrarnos en el estudio de la sociedad colonial sin recordar que la etnia, la raza y los estamentos son, justamente, estructuras objetivadas por la legalidad hispano-occidental que permiten un acceso diferencial a los recursos. La apuesta consiste en penetrar estas estructuras y develar el sustrato que permite el ejercicio de la dominación que facilita la relación mando-obediencia.

Debido a que el proceso de trabajo no solo produce un valor de uso sino la relación misma de dominación, más allá de las divisiones creadas entre los sujetos, todos acaban por formar parte de un mismo conjunto. ${ }^{13}$ Tan es así, que en un momento determinado los esclavos, los hispano-criollos y los indígenas se convirtieron, a los ojos de la élite, en un conglomerado con cierto grado de homogeneidad: plebeyos. Las múltiples categorías utilizadas para nombrar a los dominados no pueden ser reducidas a la unidad, aunque la experiencia colectiva, cotidiana y de carácter identitario contribuye a pensarlos como un colectivo plebeyo. ${ }^{14}$

11. Gladys Perri,"Los trabajadores rurales libres y la justicia. Buenos aires, fines del siglo XVIII principios del XIX", "La ley es tela de araña". Ley, justicia y sociedad rural en Buenos Aires, 1780-1830, comp. Raúl Fradkin (Buenos Aires: Prometeo Libros, 2009) 23-50; Marta B. Goldberg, "La población negra y mulata de la ciudad de Buenos Aires, 1810-1840”, Desarrollo Económico 16.61 (1976): 75-99; Miguel Ángel Rosal, Africanos y afrodescendientes en el Río de la Plata. Siglos XVIII-XIX (Buenos Aires: Dunken, 2009); Tulio Halperín Donghi, "Una estancia en la campaña de Buenos Aires, Fontezuelas, 17531809", Haciendas, latifundios y plantaciones en América Latina, comp. Enrique Florescano (México: Siglo XXI, 1975) 447-463; Carlos A. Mayo, Estancia y sociedad en La Pampa (1740-1820) (Buenos Aires: Biblos, 2004); Jorge Gelman, “Una región y una chacra en la campaña rioplatense: las condiciones de la producción triguera a fines de la época colonial”, Desarrollo Económico 28.112 (1989): 577-600.

12. Georg Lukács, Historia y consciencia de clase, t. 1 (Madrid: Sarpe, 1984) 81-84.

13. Lukács 196-197.

14. Lyman Johnson, Los talleres de la revolución. La Buenos Aires plebeya y el mundo del Atlántico, 17761810 (Buenos Aires: Prometeo Libros, 2013) 25. 


\section{Servicio de milicias y trabajo en las obras públicas de fortificación}

El 19 de enero de 1772 el comandante de la guardia de la Esquina del Carcarañá, Nicolás Senet, se dirigió al gobernador de Buenos Aires solicitando ocho peones de la Compañía de Naturales de la Capilla del Rosario para la construcción de los ranchos de dicha guarnición. Estos serían destinados al corte de paja para techar, los que le fueron aprobados poco más de una semana después. ${ }^{15} \mathrm{Al}$ mes siguiente, Senet solicitó a Buenos Aires que se resolviese la situación financiera de la guardia porque los gastos y retrasos en los pagos demostraban que requerían de mayores recursos que otras. ${ }^{16}$ En este marco, elevó un extenso escrito en el que comunicó una serie de cuestiones y propuestas:

Señor Gover[nad]or y Cap[itan] Jeneral

Muy señor mio de la tropa de Vicente Alagon, en las petacas q[u]e conducía Juan Anto[ni]o Barela, se encontraron los efectos contenidos en la noticia adjunta, y decomize, por no estar inclusos en la licencia q[u]e obtuvo de VS.

Después de solidas reflecsio[n]es y experiencia adquirida de este país, me veo constituido a representar aVS es indispensable que los Ranchos para la tropa sean de alguna segura consistencia, por los motivos siguientes.

La Cituacion de esta Guard[i]a en un paraje cuia intemperie cruelizima, no permiten que existan mucho tiempo las casas de paja, y de serlo ocurrirán con frecuencia nuevos gastos, o quedara la tropa sin abrigo: siendo de la ultima importancia no se aloje en casas particulares, en donde obcervada en sus movi[mien]tos, consecuente resultan infructuosas sus opera[cion] es y mucho menos en aloja[mien]to tan indeleble, pueden azegurarce los presos, ó efectos que se digan de custodiar, interin se emplea la Partida en alcance de otros delincuen[t]es, o apreen[si]on de contra[ban]do aziendo la escasez de paja, y madera, sea mas fácil un Rancho de adobes q[u]e de otro material, para ese fin e dispuesto se empiecen a cortar los precisos, prometiendo[l]e q[u]e mediante siento y ochenta pesos quede concluida la obra con alguna formalidad lo $\mathrm{q}[\mathrm{u}] \mathrm{e}$ sin duda no se verificaría si la tuviese a su cargo agan particular pues ordinaria[men]te antepone su interés al desempeño de la comisión que se les encarga, suplicando â VS se sirva disponer se me entregue la cantidad expresada, para avivar el trabajo, porque la desconfianza de estas jentes imposibilita se ejecute con promptitud, este motivo me ha presisado en detener los presos de quienes son las declara[cion] es adjuntas, mas contra todas mis esperanzas por falta de pricio[n]es se an ido no obstante la centinela de vista, y la exacta vigilancia de los drag[on]es siendo esta igual[men]te la causa de no executar el arresto de algunos delincuentes de quien tengo noticia, y espero remitir a VS luego q[u]e lleguen â mi poder, las $\mathrm{q}[\mathrm{u}] \mathrm{e}$ con toda sumición solicito en la lista incluza.

Respecto $\mathrm{q}[\mathrm{u}] \mathrm{e}$ en esta provincia los jeneros valen mas caros $\mathrm{q}[\mathrm{u}] \mathrm{e}$ en buenosaires, suplico â $V S$ se digne permitir venda los efectos decomisados q[u]e constan en la minuta; atento $\mathrm{q}[\mathrm{u}] \mathrm{e}$ en la ciudad

15. Agustín Rasal, "Declaración del sargento que decomiso las mulas", Esquina, 19 de enero de 1772. AGN, Buenos Aires, Colonia, sala IX, legajo 1-4-4;"En esta ocasión doy la orden”, Buenos Aires, 27 de enero de 1772. AGN, Buenos Aires, Colonia, sala IX, legajo 1-4-4, s.f.

16. Nicolás Senet, "Señor governador y capitan general", Esquina, 8 de febrero de 1772. AGN, Buenos Aires, Colonia, sala IX, legajo 1-4-4, s.f. 
apenas importaran los gastos $\mathrm{q}[\mathrm{u}] \mathrm{e}$ ocacio[n]en y vendidos aquí pueden sufragar parte de lo q[u]e se a de espender en la presente $O$ darles el destino q[u]e la considera[ci]on de VSra deter[min]e suplicándole se aga cargo de lo contenido en la carta q[u]e me escribe Gusman. ${ }^{17}$

El comandante Senet resolvió construir con adobes cocidos al sol por ser más sólidos que la paja, para lo cual se sirvió de lo decomisado para sufragar los gastos, aunque solicitó 180 pesos que gastaría en los soldados (peones). Los límites del proyecto de Senet no solo los establecía Buenos Aires, sino también los milicianos, quienes evidentemente habían puesto condiciones a la obra, y el dinero que debía servir para dinamizar las tareas o "para avivar el trabajo", ya que, como lo expresa Senet, "la desconfianza de estas jentes imposibilita se ejecute con promptitud".

En definitiva, los milicianos no pensaban trabajar sin incentivos con lo cual dejaban en evidencia la capacidad que tenían para establecer sus condiciones de labor. Esto exige pensar al miliciano más allá de su posición de subalterno castrense; por ejemplo, la Compañía de Naturales propuso la utilización del término de "peones", esto nos obliga a considerar a los milicianos en términos sociolaborales. Si bien son peones en tanto trabajan, no obstante, la extracción social de la que vienen también los constituye como tales. Por lo tanto, "estas jentes" seguían siendo peones de trabajo aun en la milicia y a los ojos de sus oficiales militares emergían como milicianos-trabajadores. Esta oficialidad castrense se construyó por repulsión a su inmediato subalterno, además, en el mismo proceso lo homogeneizó en un colectivo plebeyo (hispano-criollos, mestizos y afrodescendientes).

Las sospechas de Senet se materializaron, por lo que escribió otra misiva extensa sobre el estado de la obra: "por ahora esta suspensa por averse ausentado sin el menor fundamento los Peones que VS dispuso diese para este fin de la Comp[añí]a de los Naturales del Rosario teniendo fuertes consecuencias que por esta causa se Inutilice lo adelantado y se aga infructuoso lo ya espendido". ${ }^{18}$ Los milicianos-trabajadores habían encontrado en el abandono del lugar una estrategia social para resistir a las condiciones impuestas.

Las relaciones laborales suponen un cierto grado de fiabilidad en el que ambas partes cumplirán lo pactado, lo que el derecho laboral llama "principio de buena fe". En el momento en que una de las partes teme el incumplimiento lo notifica o se retira. La "desconfianza" de los milicianos-trabajadores se materializó en una especie de fuga. La frontera bonaerense ofrecía una multiplicidad de posibilidades para obtener el sustento (acceso a la tierra de hecho, alta demanda estacional de mano de obra,jornales en moneda, una frontera abierta con recursos del comercio clandestino, entre otros) con lo que el servicio de milicia representaba una carga a los paisanos. ${ }^{19}$

17. Nicolás Senet, "Señor governador y capitan jeneral", Esquina, 5 de abril de 1772. AGN, Buenos Aires, Colonia, sala IX, legajo 1-4-4, s.f. Cursiva del autor.

18. Nicolás Senet, "Señor governador y capitan general", Esquina, 5 de junio de 1772.AGN, Buenos Aires, Colonia, sala IX, legajo 1-4-4, s.f.

19. Roberto Di Stefano, "El mundo rural rioplatense colonial: una cuestión abierta", Boletín del Instituto de Historia Argentina y Americana "Dr. Emilio Ravignani” 4 (1991): 117-128. 
En julio de 1772 el comandante Nicolás Senet viajó a Tucumán quedando a cargo del destacamento el sargento Agustín Rasal [Rassal o Razal], quien notificó a Buenos Aires que había llegado el capitán de la Compañía de Naturales con (nuevos) soldados. Una vez más, el problema era la ausencia de recursos para cubrir la ración diaria:

participo â VS para q[u]e disponga lo mas conveniente pues en el dia ê comprado quatro lib [ra]s de Tabaco y seis de Yerba y de la carne les suministro la Razion correspond[ien]te anotando los Dueños de las reses para el regreso â esta Guardia mi com[andan]te darle la noticia yndividual para el cumplimiento.

Quisiera S[eñ]or para mi mejor acierto q[u]e VS me diese las Luces q[u]e en la ocasión se me ofrecen para mi desempeño pues mi deseo es acertar en todo espero de la Venignidad de VS consolarme en lo $\mathrm{q}[\mathrm{u}]$ e llevo pedido y esperando las Ordenes q[u]eVS se sirba mandarme quedo rogando a D[io]s g[uar]de la Vida deVS m[ucho]s a[ño]s. ${ }^{20}$

Aunque el sargento solicitaba que le "diese las luces", a simple vista se puede comprender que es atinado en el modo de tratar con los milicianos-trabajadores. La inmediata adquisición de los bienes necesarios a la ración (carne, yerba mate y tabaco) impuso a Buenos Aires los términos de la construcción. El 11 de agosto, Rasal obtuvo lo solicitado, como correspondía a la época, contra declaración de lo gastado. ${ }^{21}$ En síntesis, el proceso de la obra construida muestra que Senet fue incapaz de generar las estrategias sociales para preservar y utilizar la mano de obra miliciana y el temor a la insubordinación devino en fuga, como contracara, el sargento Rasal pudo resolver el dilema con carne y "vicios".

El entramado social propio del universo tardocolonial deja entrever la existencia de prácticas culturales que facilitaban — cuando no aseguraban- las relaciones sociolaborales y de dominación. En este marco, los "vicios" funcionaban como facilitadores que disminuían la conflictividad social e invisibilizaban la dominación. Al afirmar que "Después de solidas reflecsio[n]es y experiencia adquirida de este país", el comandante Senet nos hace suponer que era un español-peninsular. Luego se puede observar que en ningún momento manifiesta el modo en que cubriría o cómo estaría compuesta la ración de los milicianos-trabajadores, lo cual se vincula a la supuesta "desconfianza" de la que acusó a estos frente al pago y que se materializó con la fuga. ${ }^{22}$

Las prácticas sociales son herramientas culturales que permiten atemperar situaciones de conflictividad. El problema es que forman la parte no escrita del comportamiento social, así, aquellos sujetos ajenos al grupo —que desconocen dichas prácticas - tienden a irrumpir o chocar con la "armonía" de las relaciones

20. Agustín Rasal, “Señor governador y capitan general”, Esquina, 8 de julio de 1772. AGN, Buenos Aires, Colonia, sala IX, legajo 1-4-4, s.f. Cursiva del autor.

21. Agustín Rasal, “Del sargento Agustín Rasal”, Esquina, 11 de agosto de 1772. AGN, Buenos Aires, Colonia, sala IX, legajo 1-4-4, s.f.

22. Nótese que Senet no interpretó esta acción como motín ni como deserción. 
sociales de dominación. Si bien el ingreso de sujetos al conjunto de las relaciones sociales permite a los dominados modificar la correlación de fuerzas, con lo que obtienen mejoras en sus condiciones de labor/vida, al parecer, fue la actitud de Nicolás Senet la que no pudo congeniar con los intereses de los plebeyos de la frontera porteña, ya que la simple incorporación de carne y los "vicios" — a la relación social - resolvió el conflicto. El sargento Rasal era una persona de mayor experiencia, en consecuencia, supo proveer a los milicianos-trabajadores de su ración y porción de "vicios". ${ }^{23}$ En síntesis, el sargento conocía las prácticas culturales, quizás por su edad, gracias a lo cual logró menguar el conflicto mando-obediencia y finalizar las obras de los cuarteles.

Finalmente, el 19 de enero de 1776 un temporal arrasó el cuartel de paja, la cocina y parte de la habitación. El nuevo comandante Antonio Pérez Dávila propuso reconstruirlo con adobes como el fuerte de Pergamino, solicitó que le habilitaran 200 pesos y ocho hombres de la Compañía de Indios de Los Arroyos, además, propuso agregar corrales para los caballos. ${ }^{24}$ La práctica de servirse de las milicias de vecinos para realizar obras de construcción se encontraba diseminada por la frontera bonaerense. En mayo de ese año se convocó a los blandengues (soldados regulares) para asentarse en la nueva guardia de Rojas, a quienes se les pagaría puntualmente. ${ }^{25} \mathrm{Al}$ mes siguiente se puso a cargo de la obra a Marcos Pineda acompañado de milicianos de la Compañía de Naturales de Los Arroyos que "concurren gustosos". ${ }^{26}$ En julio se fugaron 16 pardos, y en septiembre se detuvo la obra por la falta de materiales y milicianos-trabajadores. ${ }^{27}$ En octubre, el sargento mayor Diego Trillo aseguró estar dispuesto a construir dicho fuerte, pero para ellos requería de la tropa necesaria. ${ }^{28}$ La obra se concluyó en julio de 1780 , mientras se disponían a mudar a los milicianos-trabajadores para reparaciones en Salto. ${ }^{29}$

La utilización de milicianos-trabajadores, e incluso de blandengues, para labores ajenas a lo castrense aparece como cotidiana, a pesar de encontrarse vedada por

23. Nicolás Senet, "Señor governador y capitan general", Esquina, 15 de junio de 1772. AGN, Buenos Aires, Colonia, sala IX, legajo 1-4-4, s.f.

24. Antonio Pérez Dávila, "Señor governador y capitan general”, Esquina, 19 de enero de 1776. AGN, Buenos Aires, Colonia, sala IX, legajo 1-4-4, s.f.

25. Diego Trillo, "Excelentísimo señor virrey", Fontezuelas, 31 de mayo de 1779. AGN, Buenos Aires, Colonia, sala IX, legajo 1-4-4; Buenos Aires, "Al sargento mayor del Partido de Arrecifes", 8 de mayo de 1779. AGN, Buenos Aires, Colonia, sala IX, Legajo 1-4-1, s.f.

26. Diego Trillo, "Excelentísimo señor virrey", Fontezuelas, 25 de junio de 1779. AGN, Buenos Aires, Colonia, sala IX, legajo 1-4-4; Juan Hernández, "Excelentísimo señor”, Rojas, 16 de junio de 1779. AGN, Buenos Aires, Colonia, sala IX, legajo 1-5-1, s.f.

27. "A don Juan Antonio Hernández", Buenos Aires, 11 de julio de 1779. AGN, Buenos Aires, Colonia, sala IX, legajo 1-5-1; Juan Hernández, "Excelentísimo señor”, Rojas, 30 de septiembre de 1779. AGN, Buenos Aires, Colonia, sala IX, legajo 1-5-1, s.f.

28. Diego Trillo, "Excelentísimo señor virrey", Fontezuelas, 15 de octubre de 1779. AGN, Buenos Aires, Colonia, sala IX, legajo 1-4-4, s.f.

29. Juan Hernández, “Excelentísimo señor”, Rojas, 20 de julio de 1780.AGN, Buenos Aires, Colonia, sala IX, legajo 1-5-1, s.f. 
las reglamentaciones que la ordenaban. En particular, la Real Declaración de 1767 especificaba que no se utilizaran las milicias si "no es para asuntos del servicio", ${ }^{30}$ prohibición que ya estaba presente en varias disposiciones reales, debido a que las fábricas y fortificaciones eran propias del gremio pertinente. ${ }^{31}$ Únicamente en la "Instrucción reservada" del conde de Floridablanca escrita para Carlos III en 1787 se considera la utilidad disciplinaria del empleo de las tropas en los trabajos públicos. $^{32}$

En el presupuesto de reconstrucción del Fuerte de San Miguel del Monte se explicita que "siempre que los comandantes no miren la conservación de su puesto con algún esmero, haciendo los reparos indispensables, con los Blan[dengue]s de sus compañías, es preciso vayan en aumento los defectos". ${ }^{33}$ El objetivo era que los blandengues realizaran reparaciones de mantenimiento en las estructuras militares. En concreto, los blandengues y ocho presidiarios construyeron el foso perimetral de la guarnición de Chascomús, además, cortaron entre 18,000 y 20,000 adobes. ${ }^{34}$ También el 2 de septiembre de 1789 terminaron las reparaciones del fuerte de Pergamino utilizando como trabajadores a milicianos, blandengues y presidiarios. ${ }^{35}$

\section{Milicianos-trabajadores, vicios e insubordinación}

Los notables locales y la élite porteña impusieron este tipo de trabajos como parte del servicio a la Corona casi sin pagar jornales. Aunque la documentación expresa la necesidad de proveerlos de su ración, mientras que se solicita que el prest no se atrase. Al igual que Senet, muchos de los oficiales castrenses temieron la insubordinación de los milicianos-trabajadores. Debido al atraso del prest, el sustento cotidiano mantenía a los hombres en el servicio, evitaba su esparcimiento o abierta deserción. La ración en la mayoría de los casos se componía de carne, yerba mate

30. "Título IX", Real Declaración sobre puntos esenciales de la ordenanza de milicias provinciales de España, que interin se regla la formal, que corresponde à estos Cuerpos, se debe observar como tal en todas sus partes (Madrid: Oficina de Antonio Marín, 1767) 200.

31. En el Libro III, Título X, véase “Ley XXII. Que los capitanes generales y cabos honren á los soldados, no se sirvan de ellos, y hagan acudir á su obligacion", Recopilación de leyes de los Reinos de las Indias, t. 2 (Madrid: Boix, 1841) 54. A propósito de las fábricas y fortificaciones, véase el "Título VI" del libro III, Recopilación de leyes 36-39.

32. Conde de Floridablanca, "Instrucción reservada que la Junta de Estado creada formalmente por decreto de este dia (8 de julio de 1787), deberá observar en todos los puntos y ramos entregados a su conocimiento y examen”, Gobierno del señor rey don Carlos III, ó instrucción reservada para la dirección de la Junta del Estado que creó este monarca (París: Imprenta de Crapelet, 1838) 242.

33. Francisco Balcarce, “Excelentísimo señor”, Luján, 11 de junio de 1784. AGN, Buenos Aires, Colonia, sala IX, legajo 1-7-4, s.f.

34. "El capitán de la Compañía de Blandengues", Buenos Aires, 18 de diciembre de 1784. AGN, Buenos Aires, Colonia, sala IX, legajo 1-7-4, s.f.

35. Francisco Balcarce, “Excelentísimo señor”, Luján, 2 de septiembre de 1789. AGN, Buenos Aires, Colonia, sala IX, legajo 1-6-3, s.f. 
y tabaco. La ausencia de una composición tan elemental podía cundir en la resistencia no violenta o simplemente en el freno de una obra pública de fortificación.

El 4 de julio de 1774, Nicolás Senet escribió la "Relación de los individuos desertados y los motivos de su fuga", en la cual explicaba pormenorizadamente cada caso. Los desertores fueron seis. El primero, el dragón Luis González con quien Senet fue hasta Mendoza, al regresar salieron para Tucumán y en el viaje "empezó a embriagarse con total abandono y al cavo de estos aviendose absolutam[en]te descompuesto el sentido" terminó por fugarse. ${ }^{36}$ El segundo, Ricardo Muñoz que recibió una fuerte reprimenda por promiscuo, luego de una diligencia dijo que debía irse porque su padre se moría en Córdoba, pero se fugó robando al sargento un par de pistolas y debiendo 4 pesos. El tercero, el dragón Ramón García de origen paraguayo. Relata Senet que "después de haver disfrutado de una mesa regular acosta de mi bolsillo el pan correspondiente y una botella de vino se junto con un paisano suio" y por extrañar a su madre se fugó con el caballo, un par de estribos y de reales que le "avia suplido". 37

El cuarto, Antonio Castro un chileno enviado por desertor, de "genio complejo", que autorizado para ir a Coronda volvió un mes y medio después y fue reprendido. Luego pidió permiso para ir a Buenos Aires de donde trajo dos mujeres, fue castigado seis días en el cepo y obligado a devolver las "prostitutas", finalmente, se fugó. ${ }^{38} \mathrm{El}$ quinto, Agustín Moreno, estando en Buenos Aires desarmó un centinela a garrotazos, cuando se le reprendió trató al sargento "como si fuese ermano suio" e intentó matarlo a traición, por lo cual quedó preso y en espera de ser remitido a Buenos Aires los oficiales locales - los que "procuraban exasperarlo" con los vecinos - clamaban para liberarlo, porque, según Senet, "subsiten creiendo que yo exaspero a la tropa y con este motivo se desertan los soldados de esta guardia provandose claram[ent]te lo contrario con lo q[u] expongo sobre las circunstancias de los q[u]e se an ausentado de ella". ${ }^{39}$ Finalmente, lo envió a Buenos Aires con una carta y desertó.

El sexto era el madrileño Estalislado La Torre quien desertó del Regimiento de Caballería de Dragones Borbón y Pavía cuando era

destinado a esta guardia en la cual sibsitia algunos meses en continua discordia con sus compañeros diciendo de mi mil bienes por los continuos favores $\mathrm{q}[\mathrm{u}] \mathrm{e}$ le concedia entre otros la diaria asistencia de comida estando sano y otras mas cuidadosa las varias vezes $\mathrm{q}[\mathrm{u}] \mathrm{e}$ estuvo enfermo no reservando ni faltándole todos los sinples y medicamentos necesarios (lo q[u]e e puesto en execucion con los demás siempre $\mathrm{q}[\mathrm{u}] \mathrm{e}$ se a ofrecido) pero ingrato a mis obsequios a cada instante daba merito de ser apremiado. ${ }^{40}$

36. Nicolás Senet, "Relación de los individuos desertados y los motivos de su fuga", Esquina, 4 de julio de 1774. AGN, Buenos Aires, Colonia, sala IX, legajo 1-4-4, f. 1r.

37. Senet, "Relación de los individuos", f. 1v.

38. Senet, "Relación de los individuos", ff. 1v-2r.

39. Senet, "Relación de los individuos", f. $2 \mathrm{v}$.

40. Senet, "Relación de los individuos", f. 3r. 
Lo envió a Buenos Aires, y debido a la demora lo puso preso. Ya liberado le robó al sargento unas pertenencias y a Senet dos caballos, unos estribos y la cincha del recado. Lo que se repite es que Senet intentó generar lazos con sus soldados y la insubordinación fue la que terminó en acciones de castigo seguidas de la deserción.

Ahora bien, dos de estos casos muestran cómo Senet proveyó de bebidas ("vicios") a los soldados de modo tal que se embriagaron. La distribución de los "vicios" en las tropas parece mantener una constante, ya que por lo general los bienes entregados eran yerba mate y tabaco, mientras que las bebidas alcohólicas por sus efectos debieron estar prohibidas para la tropa. ${ }^{41}$ No obstante, la "Relación de individuos" de Senet evidencia que los oficiales entregaban bebidas alcohólicas personalmente para soslayar la violencia inherente a las relaciones de dominación.

En dicha "Relación de individuos" se incluyó una nota del sargento Rasal que sintetiza nuestra propuesta:

aver presenciado el buen trato que les adado sin que ningún tiempo precedido exasperación ni castigo que no aya sido a la presisa y en caso abslutam[en]te, Yndispensables y siempre con la maior moderación antes bien mucho cariño subministrándoles los alimentos y vevidas que pasa si tenia y socorrerlos con las medicinas que se an ofrecido en todas yndisposiciones y Finalm[en]te procurando subordinarlos con el modo mas afable para que entre ellos resultase una buena armonía no solo a los presentes sino a cuantos an estado destacados. ${ }^{42}$

Los mecanismos que permiten la subordinación son parte constitutiva de las relaciones sociales de dominación. Para ello los sujetos desarrollan prácticas culturales concretas que facilitan el funcionamiento de estos mecanismos. En un contexto complejo, el comandante de la guardia debió lidiar con la insubordinación de los milicianos-trabajadores y la "deslealtad" de sus pares castrenses que intentaban incomodarlo con la población local. En apariencia, la insubordinación de 1772 en la que los peones se retiraron de la obra se encontraba en franca oposición al "mucho cariño subministrándoles los alimentos y vevidas" de que hablaba el sargento en 1779. La solución y el problema eran los "vicios" de la tropa, los cuales, sumados a la incapacidad de Senet para insertarse positivamente en la estructura de las relaciones sociales, le impidieron conseguir la subordinación de sus soldados.

El miedo a la fuga/deserción, la desconfianza que transmitieron a Senet y las acciones concretas de indisciplina limitaron el poder del dominador. La costumbre, aunque era inmaterial, supuso un habitus concreto de acción que se enmarcaba en

41. Eduardo Iraola, "Los bienes de consumo de los sectores populares en el espacio rioplatense (1750-1820). Una propuesta de análisis comparativo" (Ponencia, XXXII Encuentro de Geohistoria Regional y Simposio sobre el estado actual del conocimiento del Gran Chaco Meridional, Universidad Nacional del Nordeste, 2012). https://iighi.conicet.gov.ar/wp-content/uploads/ sites/29/2017/07/XXXII-EGHR-ActasDigitales.pdf (28/06/2018).

42. Senet, "Relación de los individuos", ff. 4r-4v. 
prácticas culturales que presumían espacios de acción que no solo limitaban a la élite dominante, sino que también acababan por cristalizar la dominación misma. ${ }^{43}$ De modo similar, la práctica de servirse indistintamente de la mano de obra miliciana y blandengue constituyó un proceso de formación de un colectivo plebeyo en el que confluían paisanos hispano-criollos, mestizos, indígenas y afrodescendientes, quienes fuera de las guarniciones, está de más decir, formaban parte de la peonada. Por lo tanto, la estructura castrense no hacía otra cosa que reproducir las mismas relaciones sociales de la vida cotidiana de la frontera bonaerense.

En 1790, el alférez de milicias Fernando Albandea fue designado para reemplazar al alcalde en las obras de reabrir el riacho de Baradero. ${ }^{44}$ En pocas semanas se encontraba habilitado un brazo del curso de agua que corre hacia el puerto de San Pedro. No obstante, el alférez informó sobre la necesidad de ampliar la obra:

pongo en Noticia a S.Ex[celenci]a Como de este Puerto al de las Conchas esta perdida la Nabegacion mas útil a Causa de estar cerrada la Boca de el Rio de el Baradero precidiendo el informe del Pueblo de el Baradero y nabegasión de el Parana allando su Ex[celenci]a por combeniente se facilite este transito yo me ofresco con buena voluntad a abrirle Boca en parage $\mathrm{q}[\mathrm{u}] \mathrm{e}$ la Corriente de el Parana asegure susucistencia de Conformidad $\mathrm{q}[\mathrm{u}] \mathrm{e}$ puedan dentrar $\mathrm{y}$ salir Lanchas Barcos de el Paraguay todo lo franqueare con un corto auxilio. ${ }^{45}$

Albandea había logrado cumplir con su comisión y buscaba ampliarla para asegurar la apertura al tránsito regional. ${ }^{46} \mathrm{La}$ semana siguiente se aprobó la obra y el "corto auxilio" que solicitaba por lo que debía dar detalle:

Con fecha de 13 de 9bre recebí una de S. Ex[celenci]a el dia 4 de Diciembre en la q[u]e me Ordena le informe de el auxilio indispensable $\mathrm{q}[\mathrm{u}] \mathrm{e}$ sea necesario para el nuebo proyecto de franquear la nabegación $\mathrm{p}[\mathrm{o}] \mathrm{r}$ el Rio de el Baradero.

Se nesecitan 40 hombres para los trabajos, 20 palas 20 hazad[a]s anchas= para la asistencia de los trabajan 2 tercios de yerba, $1^{\circ}$ Hanega de $\mathrm{Sa}^{47} 2$ arobas de Tabaco $=$ en q[uan]to a la carne será el consumo a proporción de el trabajo yo la administrare con arreglo q[u]e me sea posible al fin de la obra dare la noticia a S ex[celenci]a, si los trabajadores han de ser indios y mulatos aquí

43. Edward Palmer Thompson, Costumbres en común (Barcelona: Crítica, 1995) 122.

44. Joachin del Riego, "Al alférez de milicias don Fernando Albandea”, San Pedro, 30 de septiembre de 1790. AGN, Buenos Aires, Colonia, sala IX, legajo 1-4-2, s.f.

45. Fernando Albandea, "De don Fernando Albandea", Baradero, 7 de noviembre de 1790. AGN, Buenos Aires, Colonia, sala IX, legajo 1-4-2, s.f.

46. Nicolás de Arredondo, "Enterado de su carta", Buenos Aires, 13 de noviembre de 1790. AGN, Buenos Aires, Colonia, sala IX, legajo 1-4-2, s.f.

47. El peso de una fanega de sal equivalía a 51,5 kgs.Véase José ManuelVázquez Lijó, "Sal para pesquerías en la España del siglo XVIII", A articulação do sal português aos circuitos mundiais: antigos e novos consumos, comp. Inês Amorim (Porto: Universidade do Porto, Instituto de História Moderna, 2008) 152. 
serca hai compañías de estos y me son utiles para lograr las proporsiones de el tiempo $\mathrm{P}[\mathrm{o}] \mathrm{r} \mathrm{q}[\mathrm{u}] \mathrm{e}$ residen en estas inmediaciones. ${ }^{48}$

En una pormenorizada devolución el virrey aprobó los trabajos y le ordenó, primero, que el sargento mayor Antonio Ulloa franquease los 40 hombres en mitades de las Compañías de Indios y Pardos, luego de que su símil, Felipe Martínez, contribuyese en ello incluso en la necesidad de trabajadores. A los alcaldes les solicitó que exigiesen al vecindario el aporte en especie o pecuniario según sus facultades para reunir la carne, la sal, un tercio de yerba, una arroba de tabaco, además, le sugirió que las herramientas se las solicitase al vecindario con el fin de evitar los costos de traslado. Finalmente, propuso "para que puedan adelantarse lo posible prebengo higualmente a los citados Alcaldes que cuiden de destinar â ellas algunas Gente ociosa y de malas costumbres". ${ }^{49}$

Más allá de los cambios en el origen de las herramientas y de los soldados, se hace notable tanto la reducción del monto de yerba mate y tabaco como el costo que recayó en los pobladores locales. Este tipo de decisiones tomadas en Buenos Aires supuso una imagen según la cual a los plebeyos de la frontera porteña en cuanto súbditos de la Corona debía tratárselos como "sirvientes" que debían dar su aporte al procomún. ${ }^{50}$ Los informes de la guardia de San Pedro dejan entrever el conflicto entre las estrategias de control social de quienes ejercían de modo efectivo la justicia y policía frente a quienes se manifestaban por fuera de ello. ${ }^{51}$ Además, la utilización del trabajo forzado de "ociosos", "vagabundos" e incluso de "presos" no solo debe vincularse a estrategias de aprovechamiento de la mano de obra, sino a una estrategia de disciplinamiento social.

La inmediatez de la primera obra contrasta con las trabas para su continuación. Las raciones no se lograron reunir, los vecinos acusaban problemas, mientras los informes de Albandea reclamaban las condiciones solicitadas. ${ }^{52}$ Este alférez justificó en noviembre de 1791 lo avanzado y propuso iniciar las obras en otro momento, previo "acopio de rasiones $\mathrm{p}[\mathrm{ar}] \mathrm{a}$ los trabajadores estas serán las $\mathrm{q}[\mathrm{u}] \mathrm{e}$ indispensablem[en]te nesesite" ${ }^{53}$ La disposición de las obras debía ser en tiempo oportuno donde el río tuviera menos caudal y las tareas rurales requiriesen menos brazos. ${ }^{54}$

48. Fernando de Albandea, "Excelentísimo señor don Nicolás Arredondo", San Pedro, 8 de diciembre de 1790. AGN, Buenos Aires, Colonia, sala IX, legajo 1-4-2, s.f.

49. Nicolás de Arredondo, "Por oficio de 8 de diciembre", Buenos Aires, 22 de enero de 1791.AGN, Buenos Aires, Colonia, sala IX, legajo 1-4-2, s.f.

50. Thompson 57.

51. Joseph Roa, "Del cura del Rincón de San Pedro", San Pedro, 26 de septiembre de 1790. AGN, Buenos Aires, Colonia, sala IX, legajo 1-4-2, s.f.

52. Fernando de Albandea, "Excelentísimo señor", San Pedro, 10 de noviembre de 1791. AGN, Buenos Aires, Colonia, sala IX, legajo 1-4-2, s.f.

53. Fernando de Albandea, "Excelentísimo señor", San Pedro, 28 de noviembre de 1791. AGN, Buenos Aires, Colonia, sala IX, legajo 1-4-2, s.f.

54. Fabián Alonso y otros, "Los vagos de la campaña bonaerense: la construcción histórica de una figura delictiva (1730-1830)", El poder y la vara. Estudios sobre la justicia y la construcción del Estado en el Buenos 
Lo que subyace es que los plebeyos de la frontera bonaerense en cuanto súbditos de la Corona resultaban ser "servidores", por lo tanto, debían lozanamente entregar en lealtad su sudor por el procomún. Esto que puede parecer una tajante afirmación, no obstante, se entiende de las fuentes que denuncian a aquellos sujetos, ya fueran vecinos o transeúntes que, a decir de Francisco La Prida, "no sirven ni a Dios ni al rey". ${ }^{55}$ Entonces, será certero pensar que el poblador de la frontera como otro súbdito es considerado como "servidor".

A partir de esta concepción, el imperio hispánico y las autoridades locales pudieron extraer no solo una recaudación impositiva, sino también un excedente de trabajo. El funcionamiento del servicio de milicias de vecinos, aun antes de ser normativizado por las reformas borbónicas, ya implicaba el mantenimiento de las fortificaciones con el empleo de la mano de obra de los paisanos. Sin embargo, esta utilización de los milicianos-trabajadores también tempranamente implicó la obligación de la manutención. Ya en 1758 en Magdalena se otorgaban seis reses de ración a los que reparaban el fuerte del Zanjón, al año siguiente estos milicianos quedaron exentos de la expedición a Salinas y del refuerzo de los puestos de frontera, porque estaban ocupados en "fabricar" los cuarteles y las habitaciones. ${ }^{56}$ Por lo tanto, las fatigas del miliciano-trabajador le permitieron obtener el sustento, eventualmente un sueldo (prest) e incluso evadir obligaciones castrenses.

No obstante, tanto los milicianos como los dragones se resistieron a barrer, traer agua u otras tareas supuestamente impropias, ${ }^{57}$ mientras que los atrasos en el "pagamento" fueron motivo de conflicto constante al punto que el comandante de la guardia de Salto informara: "los soldados, me molestan por la plata" ${ }^{58}$ Mientras que en la tropa de Francisco González "toda la jente de milicias ban muy contentos y se ban desengañando con la experiencia de cumplírseles la doble de raciones y buenas cuentas de lo que necesitan no creiendo hicieran tanta bondad". ${ }^{59}$ En reiteradas oportunidades los oficiales acusaban que "escasea la gente por temor a los atrasos" ${ }^{\prime 60}$ y solicitaban el ajuste la deuda; el temor era que cundiera la desobediencia. ${ }^{61}$

Aires rural (1780-1930), comp. Raúl Fradkin (Buenos Aires: Prometeo Libros, 2007) 99-128.

55. Francisco La Prida, "De don Francisco Antonio de La Prida”, Hermanas, 20 de marzo de 1773. AGN, Buenos Aires, Colonia, sala IX, legajo 1-4-4, s.f.

56. Francisco Maguna, "Excelentísimo señor”, Buenos Aires, 1758. AGN, Buenos Aires, Colonia, sala IX, legajo 1-5-2; Bartolomé Gutiérrez Paz, "De don Bartolomé Gutiérrez Paz”, Salto, 29 de enero de 1759. AGN, Buenos Aires, Colonia, sala IX, legajo 1-4-1, s.f.

57. Agustín de Arena, "Excelentísimo señor", San Pedro, 4 de junio de 1767. AGN, Buenos Aires, Colonia, sala IX, legajo 1-4-2, s.f.

58. Bartolomé Gutiérrez Paz, "Bartolomé Gutiérrez Paz”, Salto, 3 de febrero de 1761.AGN, Buenos Aires, Colonia, sala IX, legajo 1-5-2, s.f.

59. Francisco González, “Excelentísimo señor”, 26 de diciembre de 1769. AGN, Buenos Aires, Colonia, sala IX, legajo 1-5-2, s.f.

60. Juan Hernández, "Señor, siendo del agrado", Salto, 11 de abril de 1779. AGN, Buenos Aires, Colonia, sala IX, legajo 1-5-2, s.f.

61. Juan Sarden, "De don Juan Joseph Sarden”, Buenos Aires, 24 de enero de 1782. AGN, Buenos Aires, Colonia, sala IX, legajo 1-7-4, s.f. 
Los milicianos-trabajadores pudieron desarrollar estrategias sociales que les permitieron imponer sus intereses a los oficiales. Entre ellas estaba la insubordinación, el motín, la fuga o la deserción, pero también el temor era una estrategia. Las condiciones sociales de obediencia implicaban la entrega de las raciones -incluyendo los "vicios" - y el pago del prest. Los capitanes, sargentos y comandantes sabían que la posibilidad de la desobediencia individual (deserción) o colectiva (motín) aumentaba con el incumplimiento. En enero de 1767, los vecinos estaban dispuestos a aportar carne para la construcción del fuerte de Pergamino y al oficial a cargo no le quedó más que solicitar al gobernador un poco de yerba y tabaco para el "vicio" de los milicianos-trabajadores, así, en abril finalizaron las obras. ${ }^{62}$

Los "vicios" como mecanismo social permitieron morigerar la dominación y constituyeron el elemento básico de la negociación. La simple modificación de la relación social abría la posibilidad de cambiar el volumen de los “vicios", mientras se consolidaba su presencia. Sucedió lo que tanto temía un estanciero de Samborombon "que la costumbre se haga ley". ${ }^{63}$ En 1767, se colocó una guardia avanzada en la estancia de don Noario. Este presentó su queja en Buenos Aires a lo que Bartolomé Peredo brevemente explicaba:

\footnotetext{
Ex[celentísi]mo s[eñ]or todos los perjuicios que expone dho Noario experimenta su est[anci]a y domesticos, son supuestos, pues en mi t[iem]po ni en 10 meses que estuvo mi antecesor no ha havido el menor motivo de queja, y si mucha unión entre la tropa y domésticos, mas perjudicial a aquellos que estos, porque Noario no da a sus Peones, mas que solo carne sin sal, ni yerva (que es su vicio, y costumbre en todas partes por lo que le paran poco, y viene los que no hallan otro amo)Y quando se retira de sus faenas, ayudan a gastar a los soldados la racion que de esto tienen, como la Galleta, por cuyo motivo, existen mas t[iem]po los Peones, y a los sold[ado]s a mitad del mes se les acaba la racion que también por esta razón convenia la separación deesta $\mathrm{Gu}[\operatorname{ardi}]$ a al paraje señalado. ${ }^{64}$
}

A mediados del siglo XVIII, los peones de campo recibían su jornal y manutención, y esta última estaba mínimamente compuesta por el alimento básico (carne, sal y bizcocho) y alguna proporción de "vicios" (yerba mate y tabaco). Sin embargo, el estanciero Noario, como puede observarse, intentó restringir aquello "que es su vicio, y costumbre en todas partes", por lo que únicamente los peones llegaban a esta estancia como última opción para conchabarse; claro está, la necesidad de conseguir el sustento los puso en desventaja y aceptaron condiciones laborales por debajo de lo que es "costumbre en todas partes".

62. Joseph Linares, "Excelentísimo señor”, Salto, 23 de enero de 1767. AGN, Buenos Aires, Colonia, sala IX, legajo 1-5-2; Joseph Linares, "Excelentísimo señor", Salto, 30 de abril de 1767. AGN, Buenos Aires, Colonia, sala IX, legajo 1-5-2, s.f.

63. Bartolomé Peredo, "Excelentísimo señor", 19 de diciembre de 1767. AGN, Buenos Aires, Colonia, sala IX, legajo 1-5-2, f. 4.

64. Bartolomé Peredo, "Excelentísimo señor", 19 de diciembre de 1767. AGN, Buenos Aires, Colonia, sala IX, legajo 1-5-2, f. 3. Cursiva del autor. 
Los peones de Noario y los soldados de Peredo se encontraban tan identificados entre sí que podían llegar a reconocer que la entrega de "vicios" era justa, como lo dedujo Peredo, porque era la costumbre. Lo anterior justifica a los peones más allá de que acabaran por comerse la ración de los soldados. Entonces, cabe suponer que el temor de Noario, si ya no había sido realidad, era que sus peones le exigiesen junto al jornal la entrega de "vicios".

En un orden exactamente opuesto, Joachin Morate logró convocar a 171 pobladores de Cañada de la Cruz y Pesquería que le representaron un gasto considerable "repartiendoles cuatro arrovas de Yerva, y dos de tabaco" ${ }^{65}$ El mismo elemento que permitía invisibilizar la dominación es aquel que en su ausencia podía motivar el descontento. Los capitanes, los sargentos o comandantes fueron sujetos que por su inmediatez con los milicianos-trabajadores pudieron generar lazos personales que también contribuyeron a menguar la materialidad del poder. La estrechez de estas relaciones humanas generó lealtades puntuales que, si se aceitaban bien con el óleo de los "vicios", y alguna que otra liberalidad, podían constituir auténticos contrapoderes que estaban limitados porque su propio origen apuntaba a retroalimentar el sistema en el que estaban insertos.

Por esto mismo, cuando algunos de estos jefes militares de la campaña eran removidos, podía cundir la desobediencia por la propia lealtad que alrededor de su persona se había tejido. Este es el caso de Marcos Pinedo que habiendo sido desplazado de su cargo comenzó a atacar indignado a los oficiales y a la guardia:

Señor en la ocasion del ttiempo, presentte, me beo precisado a molestar la justtificación, de Ve siendo el mottibo de ello mi anttesesor d[o]n Marcos pinedo quien con poco ttemor de Dios; y de los mandattos de Ve busca varios modos para attropellar estta guardia como haciendo burla de ella.

En primero lugar, al ttiempo de rezivirme de estta campaña Solicitto el que se lebanttasen ttodos a fin de que no me reziviesen como mejor consta, por Cartta que escrivio al Sargento Barttolome Toledo que se hallaba destacamento, en, la guardia de el pergamino después de algúntiempo bino a esta guardia sobre, el pleitto que seguía antte ve conttra $\mathrm{d}[\mathrm{o}] \mathrm{n}$ Juan Bernardo Peñalba, ybolbio a inquiettar la compañía de ttal, suerte que ya Abia bandos, en ella sin reparar los grabes daños que pudieran sobre benir; No digo otras cosas que pasaron en estte tiempo por no ser decentes, a la comunicación de Ve.

En la esttacion presentte sucede que tteniendo, Onze palos de sauze en el corral de los cavallos, perttenecienttes, a la Mag[esta]d los mismos que se hallaron en su poder de sinco carretadas que le entrego el Cap[ita]n d[o]n Jph Conti, por haverselos mandado, antesedenttementte a el, el sargentto mayor Venavides para que hizira estos quarteles, los que no hizo, ni enttrego dicha madera antes quemo, muchas mas, astta que se acabaron los quartteles del todo, como asi me los enttrego,Ysinmiramientto, el dia, dos del corriente después del abemaria se fue attropello al soldado que los ttenia a su cargo y aranco quattro, de los, onze diziendo Para quemarlos que luego bolveria por los demás y que si yo me allase capaz

65. Joachin Morate, "Excelentísimo señor", Areco, 13 de noviembre de 1770. AGN, Buenos Aires, Colonia, sala IX, legajo1-4-1, s.f. 
fuese a quittárselos me dieron parte y mande un Sargentto, con quattro soldados para que le exiviesen y los ttrajesen, las respuesttas fue apagar las luzes y salir a la puertta con dos pistolas y ttratar al sargentto $y$ soldados como se deja entender de un honbre attrebido. ${ }^{66}$

De lo anterior se entiende que Pinedo se consideraba con derecho a quitar los palos de sauce y quemarlos como propios, a pesar de esto ser un daño de considerable valor, ya que en Buenos Aires esta madera era una mercancía un tanto costosa por no ser local. ${ }^{67}$ Por otra parte, lo interesante es que, aunque no era el oficial a cargo, fue capaz de lograr, en principio, que los soldados se resistieran a recibir a quien lo relevaba en el mando, luego, con solo asistir a la guardia logró disparar la discordia entre la tropa.

Ahora bien, dicha discordia generada por Pinedo como punta de motín puede comprenderse por las lealtades verticales. Sin embargo, los milicianos eventualmente no se encontraban dispuestos a ser usados como simples trabajadores, quizás porque esto podía igualarlos al vulgo o porque no se estaba cumpliendo con alguna de las condiciones sociales: prest o "vicios". Allí las mismas lealtades que sostenían el andamiaje de la dominación se desmoronaban con violenta simplicidad y cundía la desobediencia, así lo informaba Joseph Linares:

Doy partte a Ve como oy dia de la fecha queriendo hazer ttrabaxar la gente en el reparo del fuertte, $y$ capilla, se han lebanttado ttodos diciendo q[u]e no es servicio del Rey y amonesttandoles que no solo hera Servicio del Rey sino de Dios pues era preciso repararles y que desde que se fundo la compañía hera esttilo de trabajar los soldados pues les costtaba ttodo lo que en mi ttiempo se había ttrabajado, y por que prendi a los q[u]e principio, del levantamiento reconocí que Peligraba mi vida y de algunos soldados que se binieron a la razón por lo que me fue preciso desirles que se retirasen astta dar partte aVe y para el seguro de la fronttera, y que enttre hellos no se harmase algún mottin pedi auxilio al Cap[ita]n D[o]n Juan J[ose]ph Gonzalez, el que luego esttubo con su Compañía, y se mantiene asta la disposición deVE. Es cierto Ex[celentísi]mo señor que si seles da gustto, en su desattencion para en adelante será preciso Costtear ttodo lo necesario y lo han de querer ttener por ley, es quantto ocurre y ruego a la Mag[esta]d divina le prospere y $\mathrm{q}[\mathrm{u}] \mathrm{e}$ su vida por $\mathrm{m}[\mathrm{ucho}] \mathrm{s} \mathrm{a}[\mathrm{n} o] \mathrm{s} .{ }^{68}$

El motín estalló porque los milicianos-trabajadores no consideraban que esta fuera una forma de "servicio al Rey", mientras que, la virulencia de la situación puso en peligro la vida de Linares al punto de pedir que se reforzase la guardia por seguridad. Por otra parte, no solo quería disciplinar a los milicianos-trabajadores para que volviesen a su labor, sino porque "si seles da gustto, en su desattencion para en adelante será preciso Costtear ttodo lo necesario y lo han de querer ttener

66. Marcos Pinedo, "Excelentísimo señor”, 14 de septiembre de 1776. AGN, Buenos Aires, Colonia, sala IX, legajo 1-5-2, s.f. Cursiva del autor.

67. Eduardo Iraola, "Los trabajos en la reparación del puente del Río Luján (1785-1786)” (Ponencia, I Jornadas de Historia Colonial, Universidad Nacional de Villa María, 2013).

68. Joseph Linares, “Excelentísimo señor”, Salto, 5 de febrero de 1770. AGN, Buenos Aires, Colonia, sala IX, legajo 1-5-2, s.f. Cursiva del autor. 
por ley", por lo tanto, el temor era que la demanda se hiciera costumbre y que ello diese lugar a considerarlo un derecho. Nuevamente, el problema era la reducida y difusa distancia entre la costumbre y la ley. ${ }^{69}$

\section{A modo de cierre}

Los milicianos-trabajadores aceptaron las relaciones de dominación y las tareas encomendadas siempre y cuando se respetasen algunas prácticas sociales que se consideraban parte constitutiva de las obligaciones del dominador. En este proceso histórico hubo claros avances y retrocesos que permitieron ir consolidando la obligación de entregar a la tropa yerba mate, tabaco y a veces bebidas, ya que como lo decía un oficial de la época: "porque es su vicio y costumbre en todas partes". ${ }^{70}$ En reiteradas oportunidades lograron que sus oficiales intervinieran ante la burocracia colonial para que se les aprontara el pago del prest o se les adelantase.

La documentación de época reitera el temor a la insubordinación, desobediencia, deserción, fuga, motín, entre otros. Los plebeyos de la frontera porteña desarrollaron múltiples estrategias sociales para establecer los términos en los que obedecían, al tiempo que sembraban la posibilidad de la resistencia que tantas veces estaba basada más en el temor que en los hechos. ${ }^{71}$ El modo de atemperar la fricción social algunas veces se debió a las capacidades personales de los oficiales para captar lealtades, aunque la mayor parte de las veces implicó la entrega de bienes con significado social que morigeraban la violencia inherente a la dominación.

Los milicianos-trabajadores que se le asignaron a Senet para las obras públicas de la guardia de la Esquina se fugaron de modo colectivo sin mediar violencia como lo hicieron los 16 pardos de las obras en el fuerte de Rojas. Pero también lo hicieron de modo individual otros tantos que este oficial menciona en su "Relación" como aquellos que "escasean”, es decir, que se escondían. Todas son estrategias sociales que los plebeyos de la frontera bonaerense pudieron desarrollar para resistir la dominación o imponer sus intereses a la hora de formar parte de una relación sociolaboral.

Los milicianos-trabajadores "molestan" a sus oficiales reclamando los pagos, con lo que dejaron evidencia, de ser cierta, la "desconfianza" que les adjudicaba Senet. Por estos medios, lograron compeler a sus oficiales a aceptar sus solicitudes. Por lo que Albandea rápidamente completó las tareas del riacho y solicitó ampliar su encargo con una provisión que, al percatarse de que no se le aprobaría, comenzó a enredarse en situaciones coyunturales y nunca se llevó a cabo. Dicha resistencia

69. Raúl Fradkin, “'Según la costumbre del pays': costumbre y arriendo en Buenos Aires durante el siglo XVIII", Boletín del Instituto de Historia Argentina y Americana "Dr. Emilio Ravignani" 11 (1995): 39-64; Raúl Fradkin, "Entre la ley y la práctica: la costumbre en la campaña bonaerense de la primera mitad del siglo XIX", Anuario del IEHS 12 (1997): 141-156.

70. Bartolomé Peredo, "Excelentísimo señor", 19 de diciembre de 1767. AGN, Buenos Aires, Colonia, sala IX, legajo 1-5-2, f. 3.

71. Aunque existieron ataques personales de los soldados contra sus oficiales. 
de Albandea supone la defensa de los "vicios" de su tropa y guarda similitudes con el caso de los milicianos-trabajadores del Zanjón que por medio de sus compromisos en la obra pública quedan exentos de la expedición a Salinas.

Ambas estrategias sociales (la fuga y la resistencia mediada por los oficiales) se caracterizaron por no poseer actos de violencia física o de una conflictividad de mayor envergadura. Sin embargo, los casos de Pinedo y Linares denotan que ciertas condiciones ponen dichos mecanismos en conflicto, ya sea por la lealtad a un oficial o por la resistencia abierta a trabajar, los milicianos se hicieron de una voz más imperativa. Las prácticas sociales cristalizadas en la costumbre impusieron condiciones a la dominación por lo que la intervención de un estanciero ante la burocracia colonial de Buenos Aires obtuvo la respuesta de un Peredo, quien poseía conocimiento de la praxis y objetó que "es costumbre en todas partes".

En América el trabajo compulsivo con motivo de servir al rey tomó diversas variantes, no obstante, la historiografía abordó mayormente las milicias de vecinos dentro de la historia militar ${ }^{72}$ y recientemente con tintes de historia sociopolítica. ${ }^{73}$ Sin embargo, la necesidad de fortificar la "frontera contra el indio" implicó servirse de los paisanos locales bajo prácticas de tipo laboral, lo que nos impone la necesidad de insertarlos en una historia social que considere múltiples variables de análisis.

De este modo, el sistema colonial pudo construir, mantener y reconstruir una serie de estructuras militares (guardias, fortines y fuertes) explotando el excedente de trabajo plebeyo y únicamente abonar para la reconstitución de esta fuerza de trabajo. Los conflictos surgieron en torno a las faltantes de estas mismas condiciones y explican el poder social logrado por los plebeyos para condicionar el accionar de los dominadores (oficiales y burocracia colonial). El grado de empoderamiento, claramente coyuntural, les permitió en algunas oportunidades reconocerse como parte de un mismo colectivo. Sin embargo, estas episódicas instancias de emergencia de una identidad colectiva hacen parte de una historia que aún no se ha escrito.

72. Juan Beverina, El virreinato de las provincias del Río de la Plata. Su organización militar: contribución a la "historia del ejército argentino" (Buenos Aires: Círculo Militar, 1992); Carlos Cansanello, "Las milicias rurales bonaerenses entre 1820 y 1830", Cuadernos de Historia Regional 19 (1998): 7-51; Roberto Marfany, "El cuerpo de Blandengues de la frontera de Buenos Aires (1752-1810)", Humanidades 23 (1933): 313-374.

73. Carlos Mayo y Amalia Latrubesse, Terratenientes, soldados y cautivos: la frontera (1736-1815) (Mar del Plata: Universidad Nacional de Mar del Plata, 1993); Gabriel Darío Taruselli, "Las expediciones a salinas: caravanas en la pampa colonial. El abastecimiento de sal a Buenos Aires (Siglos XVII y XVIII)”, Quinto Sol 9-10 (2005-2006): 125-149; Marisa Davio, “¿Vagos, traidores o desmotivados? Deserciones militares de sectores populares en Tucumán durante la primera mitad del siglo XIX”, Dimensión Antropológica 19.54 (2012): 29-49. 


\section{Fuentes}

\section{Manuscritas}

Archivo General de la Nación, Buenos Aires (AGN)

División Colonia

\section{Impresas}

Acuerdos del Extinguido Cabildo de Buenos Aires. Serie II. Tomo VI. Buenos Aires: Archivo General de la Nación, 1928.

Gobierno del señor rey don Carlos III, ó instrucción reservada para la dirección de la Junta del Estado que creó este monarca. París: Imprenta de Crapelet, 1838.

Real Declaración sobre puntos esenciales de la ordenanza de milicias provinciales de España, que interin se regla la formal, que corresponde à estos Cuerpos, se debe observar como tal en todas sus partes. Madrid: Oficina de Antonio Marín, 1767.

Recopilación de leyes de los Reinos de las Indias. Tomo 2. Madrid: Boix, 1841.

\section{Bibliografía}

Alonso, Fabián y otros. "Los vagos de la campaña bonaerense: la construcción histórica de una figura delictiva (1730-1830)". El poder y la vara. Estudios sobre la justicia y la construcción del Estado en el Buenos Aires rural (1780-1930). Comp. Raúl Fradkin. Buenos Aires: Prometeo Libros, 2007.

Beverina, Juan. El virreinato de las provincias del Río de la Plata. Su organización militar: contribución a la "historia del ejército argentino". Buenos Aires: Círculo Militar, 1992.

Cansanello, Carlos. “Las milicias rurales bonaerenses entre 1820 y $1830 ”$. Cuadernos de Historia Regional 19 (1998): 7-51.

Contreras Gay, José. “Las milicias en el Antiguo Régimen. Modelos, características generales y significado histórico”. Chronica Nova 20 (1992): 75-103.

Chust, Manuel y Juan Marchena Fernández. Eds. Las armas de la nación: independencia y ciudadanía en Hispanoamérica (1750-1850). Madrid: Iberoamericana / Vervuert, 2007.

Davio, Marisa. “¿Vagos, traidores o desmotivados? Deserciones militares de sectores populares en Tucumán durante la primera mitad del siglo XIX”. Dimensión Antropológica 19.54 (2012): 29-49.

Di Stefano, Roberto. "El mundo rural rioplatense colonial: una cuestión abierta". Boletín del Instituto de Historia Argentina y Americana "Dr. Emilio Ravignani” 4 (1991): 117-128.

Fradkin, Raúl. "Entre la ley y la práctica: la costumbre en la campaña bonaerense de la primera mitad del siglo XIX”. Anuario del IEHS 12 (1997): 141-156. 
. "Según la costumbre del pays': costumbre y arriendo en Buenos Aires durante el siglo XVIII". Boletín del Instituto de Historia Argentina y Americana "Dr. Emilio Ravignani" 11 (1995): 39-64.

Goldberg, Marta B. "La población negra y mulata de la ciudad de Buenos Aires, 1810-1840”. Desarrollo Económico 16.61 (1976): 75-99.

Gelman, Jorge. "Una región y una chacra en la campaña rioplatense: las condiciones de la producción triguera a fines de la época colonial". Desarrollo Económico 28.112 (1989): 577-600.

Halperín Donghi, Tulio. "Militarización revolucionaria en Buenos Aires, 18061815”. El ocaso del orden colonial en Hispanoamérica. Comp. Tulio Halperín Donghi. Buenos Aires: Sudamericana, 1978.

. "Una Estancia en la campaña de Buenos Aires, Fontezuelas, 17531809”. Haciendas, latifundios y plantaciones en América Latina. Comp. Enrique Florescano. México: Siglo XXI, 1975.

Iraola, Eduardo. "Borrachera y violencia en las milicias de la frontera del Buenos Aires tardocolonial". Anuario del PROEHAA 1.1 (2015): 19-45.

. "El precio de la fuerza de trabajo en la etapa tardo-colonial. Hegemonía, paternalismo y costumbres”. Ponencia, XII Congreso Nacional de Estudios del Trabajo, Asociación Argentina de Especialistas en Estudios del Trabajo / Universidad de Buenos Aires, 2015.

. "Los bienes de consumo de los sectores populares en el espacio rioplatense (1750-1820). Una propuesta de análisis comparativo”. Ponencia, XXXII Encuentro de Geohistoria Regional y Simposio sobre el estado actual del conocimiento del Gran Chaco Meridional, Universidad Nacional del Nordeste, 2012. https://iighi.conicet.gov.ar/wp-content/uploads/ sites/29/2017/07/XXXII-EGHR-ActasDigitales.pdf (28/06/2018).

. "Los trabajos en la reparación del puente del Río Luján (1785-1786)". Ponencia, I Jornadas de Historia Colonial, Universidad Nacional de Villa María, 2013.

Johnson, Lyman. Los talleres de la revolución. La Buenos Aires plebeya y el mundo del Atlántico, 1776-1810. Buenos Aires: Prometeo Libros, 2013.

Kuethe,Allan J. “Las milicias disciplinadas en América”. Soldados del Rey. El ejército borbónico en América colonial en vísperas de la Independencia. Eds. Allan J. Kuethe y Juan Marchena Fernández. Castelló de la Plana: Universitat Jaume I, 2005.

Lukács, Georg. Historia y consciencia de clase. Tomo 1. Madrid: Sarpe, 1984.

Marfany, Roberto. "El cuerpo de Blandengues de la frontera de Buenos Aires (1752-1810)". Humanidades 23 (1933): 313-374.

Mayo, Carlos A. Estancia y sociedad en La Pampa (1740-1820). Buenos Aires: Biblos, 2004.

Mayo, Carlos y Amalia Latrubesse. Terratenientes, soldados y cautivos: la frontera (17361815). Mar del Plata: Universidad Nacional de Mar del Plata,1993.

Néspolo, Eugenia. Resistencia y complementariedad. Gobernar en Buenos Aires. Luján en el siglo XVIII: un espacio políticamente concertado. Buenos Aires: Escaramujo, 2012. 
Perri, Gladys. "Los trabajadores rurales libres y la justicia. Buenos aires, fines del siglo XVIII principios del XIX". "La ley es tela de araña". Ley, justicia y sociedad rural en Buenos Aires, 1780-1830. Comp. Raúl Fradkin. Buenos Aires: Prometeo Libros, 2009.

Rosal, Miguel Ángel. Africanos y afrodescendientes en el Río de la Plata. Siglos XVIII-XIX. Buenos Aires: Dunken, 2009.

Taruselli, Gabriel Darío. "Las expediciones a salinas: caravanas en la pampa colonial. El abastecimiento de sal a Buenos Aires (Siglos XVII y XVIII)". Quinto Sol 9-10 (2005-2006): 125-149.

Thompson, Edward Palmer. Costumbres en común. Barcelona: Crítica, 1995.

Vázquez Lijó, José Manuel. "Sal para pesquerías en la España del siglo XVIII”. A articulação do sal português aos circuitos mundiais: antigos e novos consumos. Comp. Inês Amorim. Porto: Universidade do Porto, Instituto de História Moderna, 2008. 